\title{
Overview on Peroxiredoxin
}

\author{
Sue Goo Rhee*
}

\begin{abstract}
Peroxiredoxins (Prxs) are a very large and highly conserved family of peroxidases that reduce peroxides, with a conserved cysteine residue, designated the "peroxidatic" Cys $\left(C_{p}\right)$ serving as the site of oxidation by peroxides (Hall et al., 2011; Rhee et al., 2012). Peroxides oxidize the $C_{P}-S H$ to cysteine sulfenic acid $\left(C_{P}-\mathrm{SOH}\right)$, which then reacts with another cysteine residue, named the "resolving" Cys $\left(C_{R}\right)$ to form a disulfide that is subsequently reduced by an appropriate electron donor to complete a catalytic cycle. This overview summarizes the status of studies on Prxs and relates the following 10 minireviews.
\end{abstract}

\section{NOMENCLATURE}

As in all biology, acronyms are overwhelming in Prx literature. A few of the more frequently used acronyms are TSA, AhpC, and TPx (Rhee et al., 2005). Prx was initially identified in yeast in 1987 and named thiol-specific antioxidant (TSA), because it was thought to remove reactive sulfur species (like RS', $\mathrm{RSSR}^{-}$, or RSOOH) rather than reactive oxygen species (like $\mathrm{O}_{2}{ }^{-*}, \mathrm{H}_{2} \mathrm{O}_{2}$, or $\mathrm{ROOH}$ ) (Kim et al., 1988; 1989). Unlike enzymes known at the time to remove reactive oxygen species, purified TSA did not contain any redox cofactor such as a metal ion, heme, or flavin. Important clues to the actual enzymatic function of TSA were provided by database searches, which revealed a high sequence homology of TSA to AhpC (alkyl hydroperoxide reductase) identified in S. typhimurium in 1990 (Tartaglia et al., 1990), suggesting that TSA is also a peroxidase like AhpC. Subsequently, TSA was shown to reduce peroxides with thioredoxin (Trx) as the immediate hydrogen donor. Therefore the name of TSA was changed to thioredoxin peroxidase (TPx) in a manner analogous to glutathione peroxidase (GPx) (Chae et al., 1994a). It was then renamed Prx after realizing that certain members, for example 1-Cys Prxs, do not rely on Trx as the electron donor (Chae et al., 1994b). Proxiredoxin is now the name recommended by the Nomenclature Committee of the International Union of Biochemistry and Molecular Biology and is abbreviated as Prx or Prdx. As an example of typical Prx nomenclature, S. cerevisiae expresses five Prxs, which are two

Yonsei Biomedical Research Institute, Yonsei University College of Medicine, Seoul 120-752, Korea

${ }^{*}$ Correspondence: RHEESG@yuhs.ac

Published online 27 January, 2016

Keywords: circadian rhythm, hydrogen peroxide, peroxiredoxin, redox regulation, thiol-specific peroxidasee
2-Cys Prxs Tsa1 and Tsa2, two atypical 2-Cys Prxs Ahp1 and $\mathrm{nTpx}$ (where $\mathrm{n}$ stands for nucleus), and one 1-Cys mTpx (where $\mathrm{m}$ stands for mitochondria) [see the review by by Toledano and Huang (2016)].

\section{CLASSIFICATION}

The $\mathrm{C}_{\mathrm{P}}$ residue is conserved in all Prx enzymes. On the basis of the location or absence of the $C_{R}$, Prxs are classified into 2Cys, atypical 2-Cys, and 1-Cys Prx subfamilies (Chae et al., 1994b; Rhee et al., 2001; Wood et al., 2003b). 2-Cys Prx enzymes are homodimeric and contain two conserved $\left(C_{P}\right.$ and $C_{R}$ ) cysteine residues per subunit. The $\mathrm{C}_{\mathrm{P}}-\mathrm{SOH}$ reacts with the $\mathrm{C}_{\mathrm{R}}-\mathrm{SH}$ of the other subunit to form an intersubunit disulfide. In atypical 2-Cys PrxV, the $\mathrm{C}_{\mathrm{P}}-\mathrm{SOH}$ reacts with the $\mathrm{C}_{\mathrm{R}}-\mathrm{SH}$ of the same subunit to form an intrasubunit disulfide. Atypical 2-Cys is therefore also a 2-Cys Prx but is distinct from the 2-Cys Prx members that form an intermolecular disulfide on oxidation. Given the absence of a $\mathrm{C}_{R}, \mathrm{C}_{\mathrm{P}}-\mathrm{SOH}$ of 1-Cys Prx cannot be resolved within the Prx molecules and instead forms a disulfide with $\mathrm{C}_{\mathrm{R}}-\mathrm{SH}$ provided by other proteins or small thiol molecules (Fisher, 2011). Mammalian cells express six Prx isoforms (Prxl to PrxVI), which can be classified into 2-Cys (Prxl to PrxIV), atypical 2-Cys (PrxV), and 1-Cys (PrxVI) subfamilies (Rhee et al., 2001).

The subgrouping based on the position of $C_{R}$ is mechanistically informative as mentioned earlier. As more Prx homologs/orthologs became known later, it was clear that Prx enzymes are ubiquitously expressed, with multiple isoforms present in most organisms (three in Escherichia coli, five in Saccharomyces cerevisiae, six in Homo sapiens, and nine in Arabidopsis thaliana). A different classification system has been suggested based on bioinformatic analysis of 29 crystal structures and $>3500$ sequences of Prx enzymes that had been determined by 2010 (Nelson et al., 2011). This "global evolutionary classification" divided Prx proteins into Prx1, Prx5, Prx6, Tpx $\operatorname{PrxQ}$, and AhpE subfamilies. The biochemical and structural features and phylogenetic distributions of each of these Prx subgroups are summarized in the review by Poole and Nelson (2016). Members of the Prx1 subgroup are those referred to as "typical" 2-Cys Prxs that include mammalian Prxl to PrxIV, bacterial AhpC, and yeast TSA. Mammalian PrxV and PrxVI belong to the Prx5 and Prx6 subfamilies, respectively. Mammalian cells do not express members of the Tpx and PrxQ subfamilies.

\section{EXCEPTIONAL REACTIVITY OF PEROXIDATIC CYSTEINE}

The $\mathrm{C}_{\mathrm{P}}$ of $\mathrm{Prx}$ is oxidized by peroxides like $\mathrm{H}_{2} \mathrm{O}_{2}$, lipid peroxide, 
or peroxynitrite very rapidly with the second order rate constants for the formation of $\mathrm{C}_{\mathrm{p}} \mathrm{SOH}$ being in the range of $1 \times 10^{6}$ to $10^{8} \mathrm{M}^{-1} \mathrm{~s}^{-1}$, which are 5 to 7 orders of magnitude higher than those for small thiols (Winterbourn, 2013). The rate constants for next catalytic steps, the disulfide formation between $\mathrm{C}_{\mathrm{P}}-\mathrm{SOH}$ and $\mathrm{C}_{\mathrm{R}}-\mathrm{SH}$ and the reduction of $\mathrm{C}_{\mathrm{P}}-\mathrm{S}-\mathrm{S}-\mathrm{C}_{\mathrm{R}}$, were also measured for various Prx enzymes. Kinetic analysis also revealed that peroxides bind to Prx with submicromolar affinity. The methods used to obtain those kinetic constants for individual steps include the competitive kinetics with horseradish peroxidase or catalase or stopped flow monitoring of the change in intrinsic tryptophan fluorescence (Manta et al., 2009; Parsonage et al., 2015; Trujillo et al., 2007), which are described in the review by Winterbourn and Peskin (2016). Analyses of Prx structures with bound peroxide or peroxide-mimicking molecules revealed a model for the transition state of the peroxidase reaction (Hall et al., 2011; Nakamura et al., 2010; Perkins et al., 2015). In the model, all Prxs have an active site structure with a nearly universal sequence, $P X X X T X X C_{P}$ (where $X$ is any amino acid), as well as a conserved Arg that is distant in sequence but located nearby in the three-dimensional fold. The transition state involves an extensive hydrogen bond network, which comprises the $\mathrm{C}_{\mathrm{P}}$ thiolate anion, peroxide $(\mathrm{ROOH})$, Thr and Pro residues located within a universal PXXXTXXC $C_{P}$ active site motif as well as the conserved Arg residue. This network of hydrogen bonds thus provides a binding site for peroxide that properly aligns the substrate for attack by the CP thiolate sulfur and lowers the activation energy of the bond-breaking and bond-forming processes by stabilizing the transition state intermediate.

\section{ANTIOXIDANT ROLE OF PRXS}

Undoubtedly the peroxidase activity of Prx enzymes towards $\mathrm{H}_{2} \mathrm{O}_{2}$, organic hydroperoxides and peroxynitrite is critical to protect cellular components from oxidative damage (Fisher, 2011; Knoops et al., 2011). However, the existence of multiple peroxide-removing enzymes such as catalase, GPx, Prx, and ascorbate peroxidase (APx) within a single organism, cell, or subcellular compartment, indicates that these peroxidases are not simply for oxidant defense. For example, chloroplasts contain three Prx, two GPx, and two APx isoforms (Dietz, 2016). They use different electron donors and are linked to distinct redox networks. The significance of those multiple peroxidase enzymes in the photosynthesizing chloroplast is discussed in context of various aspects including suborganellar localization, substrate preference, and metabolic coupling in the review by Dietz (2016).

\section{PRXS AS A REGULATOR OF LOCAL $\mathrm{H}_{2} \mathrm{O}_{2}$ CONCENTRATION}

Many mammalian cell types produce $\mathrm{H}_{2} \mathrm{O}_{2}$ for the purpose of intracellular signaling in response to stimulation through various cell surface receptors (Rhee, 2006). $\mathrm{H}_{2} \mathrm{O}_{2}$ propagates receptor signals by oxidizing proteinaceous thiols such as those in protein tyrosine phosphatases (PTPs) (Lee et al., 1998), the tumor suppressor PTEN (phosphatase and tensin homolog) (Kwon et al., 2004), and ASK1 (an upstream kinase of p38 and JNK mitogen activated kinases) (Saitoh et al., 1998; Nadeau et al., 2007). The targeted thiol groups of these $\mathrm{H}_{2} \mathrm{O}_{2}$ effector proteins react several orders of magnitude more slowly with $\mathrm{H}_{2} \mathrm{O}_{2}$ compared with the $C_{P}$ residue of Prxs (Winterbourn, 2013). Given that these effector proteins are at such a competitive disadvantage, it seems likely that neighboring Prx molecules must be transiently inactivated to allow them to react with $\mathrm{H}_{2} \mathrm{O}_{2}$. One example is the inactivation of lipid raft-associated mammalian
Prxl through phosphorylation at $\mathrm{Tyr}^{194}$ in cells stimulated with growth factors (Woo et al., 2010) or inactivation of centrosomeassociated Prxl through phosphorylation at Thr ${ }^{90}$ during early mitosis (Lim et al., 2015). Another example is the inactivation of 2-Cys Prx members through reversible hyperoxidation of $C_{P-}$ $\mathrm{SH}$ (see below). By switching "off" the highly active Prxs around the sites of $\mathrm{H}_{2} \mathrm{O}_{2}$ production, the oxidants produced could reach higher levels within these foci that could then permit the oxidation of protein targets involved in signaling, processes which would normally be much too slow to compete with the oxidation of $\mathrm{Prx} \mathrm{C}_{\mathrm{P}}-\mathrm{SH}$.

\section{PRXS AS SENSORS AND TRANSDUCERS OF SIGNALING BY $\mathrm{H}_{2} \mathrm{O}_{2}$}

In an alternative scenario, redox-regulated proteins are not directly oxidized by $\mathrm{H}_{2} \mathrm{O}_{2}$, but rather their oxidation is mediated by Prx. In this case, the $\mathrm{C}_{\mathrm{p}}$ of $\mathrm{Prx}$ is rapidly and selectively oxidized by $\mathrm{H}_{2} \mathrm{O}_{2}$. The oxidized Prx, in either the sulfenic $\left(\mathrm{C}_{P-}\right.$ $\mathrm{SOH}$ ) or disulfide state ( $\mathrm{C}_{\mathrm{P}} \mathrm{S}-\mathrm{S}-\mathrm{C}_{\mathrm{R}}$ ), forms an intermolecular disulfide-linked intermediate with a bound effector protein. Resolution of the disulfide by reaction with another Cys-SH of the effector results in regeneration of reduced Prx and oxidation of the effector protein, the latter process leading to a change in effector function. The sensor-transducer function of Prxs is extensively covered in three reviews by Netto and Antunes (2016), by Latimer and Veal (2016), and by Toledano and Huang (2016), taking yeast transcription factor PAP (Vivancos et al., 2005), mammalian transcription factor STAT3 (Sobotta et al., 2015), and ASK1 (Nadeau et al., 2007) as example of $\mathrm{H}_{2} \mathrm{O}_{2}$ target protein. Taking advantage of the extreme $\mathrm{H}_{2} \mathrm{O}_{2}$ sensitivity of the $\mathrm{C}_{\mathrm{P}}-\mathrm{SH}$ of $\mathrm{Prx}$, genetically encoded $\mathrm{H}_{2} \mathrm{O}_{2}$ fluorescent probes have been devised by fusing a Prx to green fluorescent protein (GFP) or yellow fluorescent protein (YFP). In the probes, the oxidation state of Prx is transferred to cysteine residues in GFP or YFP proteins. In the review by Van Laer and Dick (2016), sensitivity and design strategies for Prx-based probes are discussed.

\section{HYPEROXIDATION OF 2-CYS PRX}

During catalysis, the peroxidatic Cys-SOH of 2-Cys Prxs is occasionally further oxidized to $\mathrm{Cys}-\mathrm{SO}_{2} \mathrm{H}$ before disulfide formation, resulting in inactivation of peroxidase activity (Yang et al., 2002). The hyperoxidation is reversed by the ATPdependent enzyme sulfiredoxin, restoring peroxidase activity (Biteau et al., 2003; Woo et al., 2003). The reversible inactivation of 2-Cys Prx through hyperoxidation has been suggested to be an evolutionary adapted mechanism for eukaryotic cells and phototropic bacteria; 1) to allow $\mathrm{H}_{2} \mathrm{O}_{2}$ to accumulate to substantial levels under certain circumstances for signaling purposes (Wood et al., 2003a); 2) to couple circadian rhythm to Prx function (O'Neill et al., 2011); or 3) to confer chaperone function to the 2-Cys Prxs in cells under severe oxidative stress (Jang et al., 2004).

\section{ROLE OF 2-CYS PRX HYPEROXIDATION IN $\mathrm{H}_{2} \mathrm{O}_{2}$ SIGNALING}

Hyperoxidized form of Prx III, a mitochondria-specific enzyme, was found to be abundant especially in the cortex of adrenal gland of mouse maintained under normal conditions. The adrenal cortex is where cholesterol is oxidized to corticosterone by cytochrome P450s in response to stimulation with adrenocorticotropic hormone. The conversion of cholesterol to corti- 
costerone is accompanied by $\mathrm{H}_{2} \mathrm{O}_{2}$ generation as the result of leaky cytochrome p450, which results in the hyperoxidation and inactivation of PrxllI (Kil et al., 2012). Inactivation of Prxlll triggers a sequence of events including accumulation of $\mathrm{H}_{2} \mathrm{O}_{2}$, activation of p38 mitogen-activated protein kinase (MAPK), suppression of steroidogenic acute regulatory protein synthesis, and inhibition of steroidogenesis (Kil et al., 2012). The coupling of CYP11B1 activity to PrxIII hyperoxidation thus provides a feedback regulatory mechanism for steroidogenesis. $\mathrm{H}_{2} \mathrm{O}_{2}$ has been increasingly recognized as an important component of cell signaling, including proliferation, differentiation, steroidogenesis, metabolism, apoptosis, and senescence. Hampton and O'Connor (2016) suggest in their review that Prxlll hyperoxidation is a critical element of apoptotic process and that PrxllI$\mathrm{SO}_{2} \mathrm{H}$ can be a biomarker of redox changes during the initiation and progression of cell death as indicated by the fact that the timing of PrxIII-SO ${ }_{2} \mathrm{H}$ accumulation during Fas-mediated apoptosis in Jurkat T-lymphoma cells corresponds to cytochrome $\mathrm{C}$ release from the mitochondria and subsequent caspase activation (Cox et al., 2008). Although numerous signaling pathways are known to be affected by $\mathrm{H}_{2} \mathrm{O}_{2}$, the underlying mechanisms are not well established. One of the better known $\mathrm{H}_{2} \mathrm{O}_{2}-$ regulated pathways is the MAPK cascade. Latimer and Veal (2016) reviewed the evidence that Prx acts on muiltiple steps of MAPK signaling pathways in various organisms.

\section{2-CYS PRX HYPEROXIDATION AND CIRCADIAN RHYTHM}

As summarized in the review by Putker and O'Neill (2016), it has been known for a while that the circadian clock regulates cellular redox state such as the ratio of $N A D(P) / N A D(P) H$. The remarkable story of the circadian oscillation of 2-Cys $\mathrm{Prx}-\mathrm{SO}_{2} \mathrm{H}$ started with the discovery of the hyperoxidation of 2-Cys Prx as a transcription-independent circadian biomarker in a green alga (O'Neill et al., 2011) and human red blood cells (O'Neill and Reddy, 2011). The rhythmic variation in 2-Cys $\mathrm{Prx}-\mathrm{SO}_{2} \mathrm{H}$ abundance was subsequently detected in various organisms including fungus, worm, fly, and mouse, suggesting that Prx hyperoxidation cycles represent a conserved, ancestral circadian mechanism (Edgar et al., 2012; Olmedo et al., 2012). Interestingly, the amounts of PrxIII-SO ${ }_{2} \mathrm{H}$ and $\mathrm{Srx}$ in the mitochondria of adrenal gland also showed daily variation (Kil et al., 2012). These results suggest that full circadian oscillation of corticosterone controlled by both the master and adrenal peripheral clocks requires the participation of the signaling pathway involving the reversible Prxlll hyperoxidation. The reversible Prxlll hyperoxidation appear to play critical role in linking metabolism also to other peripheral clocks in tissues like heart, lung, and brown adipose tissue (Kil, 2015). The oscillation in 2-Cys Prx- $\mathrm{SO}_{2} \mathrm{H}$ abundance appears to be a cellular clock output driven by an underlying rhythm in oxidative metabolism (Causton et al., 2015).

\section{CHAPERONE FUNCTION OF HYPEROXIDIZED 2-CYS PRX}

In addition to the roles in $\mathrm{H}_{2} \mathrm{O}_{2}$ signaling and circadian output, hyperoxidation confers a new function on 2-Cys Prxs-namely, that of a protein chaperone. The first evidence for this gain of chaperone function came from the observation that yeast cells deficient in both TSAs (cytosolic 2-Cys Prxs) are highly sensitive to heat shock treatment, a phenotype often associated with organisms that lack crucial chaperones (Jang et al., 2004). The chaperone function was found to be independent of peroxidase activity. Chaperone activity was also subsequently demonstrat- ed for hyperoxidized Prx in various species (Moon et al., 2005). As suggested initially for yeast TSAs, the chaperone activity observed in most species was attributed to high molecular weight species that appeared to correspond to double- or multiple-layered decameric rings, with the the high molecular weight assembly being triggered by the $C_{P}$ hyperoxidation. As pointed out by Toledano and Huang in their review (Toledano and Huang, 2016), however, neither the hyperoxidation nor the higher order oligomerization was necessary for the chaperone function of 2-Cys Prxs in certain species. Toledano and Huang (2016) also point out that the in vivo relevance of chaperone function is yet to be established.

\section{PRXS AS PAMPS AND DAMPS}

During inflammation high levels of peroxides $\mathrm{H}_{2} \mathrm{O}_{2}$, lipid hydroperoxide, and peroxynitrite) are produced by phagocytes to kill microorganisms. It has been well established that Prxs play cytoprotective antioxidant role in inflammation (Gretes et al., 2012; Sun et al., 2010). Peroxides serve also in the complex regulation of inflammatory signaling pathways, and Prxs are known to be critical modulator of the signaling peroxides (Diet et al., 2007). Recently, it has been proposed that Prxs may play key roles in innate immunity and inflammation. A 2-Cys malarial Prx from Plasmodium berghei was reported to act as a PAMP (pathogen-associated molecular pattern) by binding to a toll-like receptor on macrophages and triggering a pro-inflammatory response (Furuta et al., 2008). Moreover, exosomally released Prxs by different cells upon exposure to LPS and TNF- $\alpha$ has also been shown to act as a DAMP (host-derived damageassociated molecular patterns) to trigger inflammatory cytokines by macrophages (Mullen et al., 2015; Riddell et al., 2010; Salzano et al., 2014; Shichita et al., 2012). Those multiple, complex roles played by Prxs in inflammation are described in the review by Knoops et al. (2016).

\section{ACKNOWLEDGMENTS}

I would like to thank the Korean Society for Molecular and Cellular Biology (KSMCB) for the opportunity to organize reviews on peroxiredoxin.

\section{REFERENCES}

Biteau, B., Labarre, J., and Toledano, M.B. (2003). ATP-dependent reduction of cysteine-sulphinic acid by $\mathrm{S}$. cerevisiae sulphiredoxin. Nature 425, 980-984

Causton, H.C., Feeney, K.A., Ziegler, C.A., and O'Neill, J.S. (2015). Metabolic cycles in yeast share features conserved among circadian rhythms. Curr. Biol. 25, 1056-1062.

Chae, H.Z., Chung, S.J., and Rhee, S.G. (1994a). Thioredoxindependent peroxide reductase from yeast. J. Biol. Chem. 269 27670-27678.

Chae, H.Z., Robison, K., Poole, L.B., Church, G., Storz, G., and Rhee, S.G. (1994b). Cloning and sequencing of thiol-specific antioxidant from mammalian brain: alkyl hydroperoxide reductase and thiol-specific antioxidant define a large family of antioxidant enzymes. Proc. Natl. Acad. Sci. USA 91, 7017-7021.

Cox, A.G., Pullar, J.M., Hughes, G., Ledgerwood, E.C., and Hampton, M.B. (2008). Oxidation of mitochondrial peroxiredoxin 3 during the initiation of receptor-mediated apoptosis. Free Rad. Biol. Med. 44, 1001-1009.

Diet, A., Abbas, K., Bouton, C., Guillon, B., Tomasello, F., Fourquet, S., Toledano, M.B., and Drapier, J.C. (2007). Regulation of peroxiredoxins by nitric oxide in immunostimulated macrophages. J. Biol. Chem. 282, 36199-36205.

Dietz, K.J. (2016). Thiol-based peroxidases and ascorbate peroxidases: why plants rely on multiple peroxidase systems in the photosynthesizing chloroplast? Mol. Cells 39, 20-25. 
Edgar, R.S., Green, E.W., Zhao, Y., van Ooijen, G., Olmedo, M., Qin X., Xu, Y., Pan, M., Valekunja, U.K., Feeney, K.A., et al. (2012). Peroxiredoxins are conserved markers of circadian rhythms. Nature $485,459-464$

Fisher, A.B. (2011). Peroxiredoxin 6: a bifunctional enzyme with glutathione peroxidase and phospholipase A(2) activities. Antioxid. Redox Signal. 15, 831-844

Furuta, T., Imajo-Ohmi, S., Fukuda, H., Kano, S., Miyake, K., and Watanabe, N. (2008). Mast cell-mediated immune responses through IgE antibody and Toll-like receptor 4 by malarial peroxiredoxin. Eur. J. Immunol. 38, 1341-1350.

Gretes, M.C., Poole, L.B., and Karplus, P.A. (2012). Peroxiredoxins in parasites. Antioxid. Redox Signal. 17, 608-633.

Hall, A., Nelson, K., Poole, L.B., and Karplus, P.A. (2011). Structurebased insights into the catalytic power and conformational dexterity of peroxiredoxins. Antioxid. Redox Signal. 15, 795-815.

Hampton, M.B., and O'Connor, K.M. (2016). Peroxiredoxins and the regulation of cell death. Mol. Cells 39, 72-76.

Jang, H.H., Lee, K.O., Chi, Y.H., Jung, B.G., Park, S.K., Park, J.H., Lee, J.R., Lee, S.S., Moon, J.C., Yun, J.W., et al. (2004). Two enzymes in one; two yeast peroxiredoxins display oxidative stress-dependent switching from a peroxidase to a molecular chaperone function. Cell 117, 625-635.

Kil, I.S., Lee, S.K., Ryu, K.W., Woo, H.A., Hu, M.C., Bae, S.H., and Rhee, S.G. (2012). Feedback control of adrenal steroidogenesis via $\mathrm{H}_{2} \mathrm{O}_{2}$-dependent, reversible inactivation of peroxiredoxin III in mitochondria. Mol. Cell 46, 584-594.

Kil, I.S., Ryu, K. W., Lee, S.Y., Kim, Y. Y., Chu, S. Y., Kim, J. H., Park, S., Rhee, S. G. (2015). Circadian Oscillation of Sulfiredoxin in the Mitochondria. Mol. Cell 59, 1-13.

Kim, K., Kim, I.H., Lee, K.Y., Rhee, S.G., and Stadtman, E.R. (1988) The isolation and purification of a specific "protector" protein which inhibits enzyme inactivation by a thiol/Fe(III)/O2 mixedfunction oxidation system. J. Biol. Chem. 263, 4704-4711.

Kim, I.H., Kim, K., and Rhee, S.G. (1989). Induction of an antioxidant protein of Saccharomyces cerevisiae by $\mathrm{O} 2, \mathrm{Fe} 3+$, or 2mercaptoethanol. Proc. Natl. Acad. Sci. USA 86, 6018-6022

Knoops, B., Goemaere, J., Van der Eecken, V., and Declercq, J.P. (2011). Peroxiredoxin 5: structure, mechanism, and function of the mammalian atypical 2-Cys peroxiredoxin. Antioxid. Redox Signal. 15, 817-829.

Knoops, B., Argyropoulou, V., Becker, S., and Ferté, L., Kuznetsova, $\mathrm{O}$. (2016). Multiple roles of peroxiredoxins in inflammation. Mol. Cells 39, 60-64

Kwon, J., Lee, S.R., Yang, K.S., Ahn, Y., Kim, Y.J., Stadtman, E.R., and Rhee, S.G. (2004). Reversible oxidation and inactivation of the tumor suppressor PTEN in cells stimulated with peptide growth factors. Proc. Natl. Acad. Sci. USA 101, 16419-16424.

Latimer, H.R., and Veal, E.A. (2016). Peroxiredoxins in regulation of MAPK signalling pathways; sensors and barriers to signal transduction. Mol. Cells 39, 40-45

Lee, S.R., Kwon, K.S., Kim, S.R., and Rhee, S.G. (1998). Reversible inactivation of protein-tyrosine phosphatase $1 B$ in A431 cells stimulated with epidermal growth factor. J. Biol. Chem. 273, 15366-15372.

Lim, J.M., Lee, K.S., Woo, H.A., Kang, D., and Rhee, S.G. (2015). Control of the pericentrosomal $\mathrm{H} 2 \mathrm{O} 2$ level by peroxiredoxin I is critical for mitotic progression. J. Cell Biol. 210, 23-33.

Manta, B., Hugo, M., Ortiz, C., Ferrer-Sueta, G., Trujillo, M., and Denicola, A. (2009). The peroxidase and peroxynitrite reductase activity of human erythrocyte peroxiredoxin 2. Arch. Biochem. Biophys. 484, 146-154.

Moon, J.C., Hah, Y.S., Kim, W.Y., Jung, B.G., Jang, H.H., Lee, J.R., Kim, S.Y., Lee, Y.M., Jeon, M.G., Kim, C.W., et al. (2005). Oxidative stress-dependent structural and functional switching of a human 2-Cys peroxiredoxin isotype II that enhances HeLa cell resistance to $\mathrm{H}_{2} \mathrm{O}_{2}$-induced cell death. J. Biol. Chem. 280, 28775-28784.

Mullen, L., Hanschmann, E.M., Lillig, C.H., Herzenberg, L.A., and Ghezzi, P. (2015). Cysteine oxidation targets peroxiredoxins 1 and 2 for exosomal release through a novel mechanism of redox-dependent secretion. Mol. Med. 21, 98-108.

Nadeau, P.J., Charette, S.J., Toledano, M.B., and Landry, J. (2007). Disulfide bond-mediated multimerization of Ask1 and its reduction by thioredoxin-1 regulate $\mathrm{H}(2) \mathrm{O}(2)$-induced c-Jun $\mathrm{NH}(2)$ terminal kinase activation and apoptosis. Mol. Biol. Cell 18,
3903-3913

Nakamura, T., Kado, Y., Yamaguchi, T., Matsumura, H., Ishikawa, K., and Inoue, T. (2010). Crystal structure of peroxiredoxin from Aeropyrum pernix K1 complexed with its substrate, hydrogen peroxide. J. Biochem. 147, 109-115.

Nelson, K.J., Knutson, S.T., Soito, L., Klomsiri, C., Poole, L.B., and Fetrow, J.S. (2011). Analysis of the peroxiredoxin family: using active-site structure and sequence information for global classification and residue analysis. Proteins 79, 947-964.

Netto, L.E.S., and Antunes, F. (2016). The roles of peroxiredoxin and thioredoxin in hydrogen reroxide sensing and in signal transduction. Mol. Cells 39, 65-71.

O'Neill, J.S., and Reddy, A.B. (2011). Circadian clocks in human red blood cells. Nature 469, 498-503.

O'Neill, J.S., van Ooijen, G., Dixon, L.E., Troein, C., Corellou, F., Bouget, F.Y., Reddy, A.B., and Millar, A.J. (2011). Circadian rhythms persist without transcription in a eukaryote. Nature 469 554-558.

Olmedo, M., O'Neill, J.S., Edgar, R.S., Valekunja, U.K., Reddy, A.B., and Merrow, M. (2012). Circadian regulation of olfaction and an evolutionarily conserved, nontranscriptional marker in Caenorhabditis elegans. Proc. Natl. Acad. Sci. USA 109, 20479-20484.

Parsonage, D., Nelson, K.J., Ferrer-Sueta, G., Alley, S., Karplus, P.A., Furdui, C.M., and Poole, L.B. (2015). Dissecting peroxiredoxin catalysis: separating binding, peroxidation, and resolution for a bacterial AhpC. Biochemistry 54, 1567-1575.

Perkins, A., Nelson, K.J., Parsonage, D., Poole, L.B., and Karplus, P.A. (2015). Peroxiredoxins: guardians against oxidative stress and modulators of peroxide signaling. Trends Biochem. Sci. 40, 435-445.

Poole, L.B., and Nelson, K.J. (2016). Distribution and features of the six classes of peroxiredoxins. Mol. Cells 39, 53-59.

Putker, M., and O'Nell, J.H. (2016). Reciprocal control of the circadian clock and cellular redox state - a critical appraisal. Mol Cells 39, 6-19

Rhee, S.G. (2006). Cell signaling. $\mathrm{H}_{2} \mathrm{O}_{2}$, a necessary evil for cell signaling. Science 312, 1882-1883.

Rhee, S.G., Kang, S.W., Chang, T.S., Jeong, W., and Kim, K. (2001). Peroxiredoxin, a novel family of peroxidases. IUBMB life $52,35-41$.

Rhee, S.G., Chae, H.Z., and Kim, K. (2005). Peroxiredoxins: a historical overview and speculative preview of novel mechanisms and emerging concepts in cell signaling. Free Rad. Biol. Med. 38 , 1543-1552.

Rhee, S.G., Woo, H.A., Kil, I.S., and Bae, S.H. (2012). Peroxiredoxin functions as a peroxidase and a regulator and sensor of local peroxides. J. Biol. Chem. 287, 4403-4410.

Riddell, J.R., Wang, X.Y., Minderman, H., and Gollnick, S.O. (2010). Peroxiredoxin 1 stimulates secretion of proinflammatory cytokines by binding to TLR4. J. Immunol. 184, 1022-1030.

Saitoh, M., Nishitoh, H., Fujii, M., Takeda, K., Tobiume, K., Sawada, Y., Kawabata, M., Miyazono, K., and Ichijo, H. (1998). Mammalian thioredoxin is a direct inhibitor of apoptosis signal-regulating kinase (ASK) 1. EMBO J. 17, 2596-2606.

Salzano, S., Checconi, P., Hanschmann, E.M., Lillig, C.H., Bowler, L.D., Chan, P., Vaudry, D., Mengozzi, M., Coppo, L., Sacre, S., et al. (2014). Linkage of inflammation and oxidative stress via release of glutathionylated peroxiredoxin-2, which acts as a danger signal. Proc. Natl. Acad. Sci. USA 111, 12157-12162.

Shichita, T., Hasegawa, E., Kimura, A., Morita, R., Sakaguchi, R. Takada, I., Sekiya, T., Ooboshi, H., Kitazono, T., Yanagawa, T., et al. (2012). Peroxiredoxin family proteins are key initiators of post-ischemic inflammation in the brain. Nat. Med. 18, 911-917.

Sobotta, M.C., Liou, W., Stocker, S., Talwar, D., Oehler, M., Ruppert, T., Scharf, A.N., and Dick, T.P. (2015). Peroxiredoxin-2 and STAT3 form a redox relay for $\mathrm{H}_{2} \mathrm{O}_{2}$ signaling. Nat. Chem. Biol. 11, 64-70.

Sun, H.N., Kim, S.U., Huang, S.M., Kim, J.M., Park, Y.H., Kim, S.H., Yang, H.Y., Chung, K.J., Lee, T.H., Choi, H.S., et al. (2010). Microglial peroxiredoxin $\mathrm{V}$ acts as an inducible anti-inflammatory antioxidant through cooperation with redox signaling cascades. J. Neurochem. 114, 39-50

Tartaglia, L.A., Storz, G., Brodsky, M.H., Lai, A., and Ames, B.N. (1990). Alkyl hydroperoxide reductase from Salmonella typhimurium. Sequence and homology to thioredoxin reductase and other flavoprotein disulfide oxidoreductases. J. Biol. Chem. 265 , 
$10535-10540$

Toledano, M.B., and Huang, B. (2016). Microbial 2-Cys Prxs: insights into their complex physiological roles. Mol. Cells 39, 31-39.

Trujillo, M., Clippe, A., Manta, B., Ferrer-Sueta, G., Smeets, A., Declercq, J.P., Knoops, B., and Radi, R. (2007). Pre-steady state kinetic characterization of human peroxiredoxin 5: taking advantage of Trp84 fluorescence increase upon oxidation. Arch. Biochem Biophys. 467, 95-106.

Van Laer, K., and Dick, T.P. (2016). Utilizing natural and engineered peroxiredoxins as intracellular peroxide reporters. Mol. Cells $39,46-52$.

Vivancos, A.P., Castillo, E.A., Biteau, B., Nicot, C., Ayte, J., Toledano, M.B., and Hidalgo, E. (2005). A cysteine-sulfinic acid in peroxiredoxin regulates $\mathrm{H}_{2} \mathrm{O}_{2}$-sensing by the antioxidant Pap1 pathway. Proc. Natl. Acad. Sci. USA 102, 8875-8880.

Winterbourn, C.C. (2013). The biological chemistry of hydrogen peroxide. Methods Enzymol. 528, 3-25

Winterbourn, C.C., Peskin, A.V. (2016). Kinetic approaches to measuring peroxiredoxin reactivity. Mol. Cells 39, 26-30.

Woo, H.A., Kang, S.W., Kim, H.K., Yang, K.S., Chae, H.Z., and
Rhee, S.G. (2003). Reversible oxidation of the active site cysteine of peroxiredoxins to cysteine sulfinic acid. Immunoblot detection with antibodies specific for the hyperoxidized cysteinecontaining sequence. J. Biol. Chem. 278, 47361-47364.

Woo, H.A., Yim, S.H., Shin, D.H., Kang, D., Yu, D.Y., and Rhee, S.G (2010). Inactivation of peroxiredoxin I by phosphorylation allows localized $\mathrm{H}(2) \mathrm{O}(2)$ accumulation for cell signaling. Cell 140, 517528.

Wood, Z.A., Poole, L.B., and Karplus, P.A. (2003a). Peroxiredoxin evolution and the regulation of hydrogen peroxide signaling. Science 300, 650-653.

Wood, Z.A., Schroder, E., Robin Harris, J., and Poole, L.B. (2003b). Structure, mechanism and regulation of peroxiredoxins. Trends Biochem. Sci. 28, 32-40.

Yang, K.S., Kang, S.W., Woo, H.A., Hwang, S.C., Chae, H.Z., Kim, K., and Rhee, S.G. (2002). Inactivation of human peroxiredoxin I during catalysis as the result of the oxidation of the catalytic site cysteine to cysteine-sulfinic acid. J. Biol. Chem 277, 3802938036 . 